\title{
Innovative Technologies in Education
}

\author{
Tatyana Miroshnikova ${ }^{1, *}$ \\ ${ }^{1}$ Vladivostok State University of Economy and Service, Gogolya str., 41, Vladivostok, 690014, \\ Russia
}

\begin{abstract}
The innovative approach reflects the current state of the education system in the country. Subjects of the innovative infrastructure of the educational process ensure the socio-economic development of the economy. The task of expanding the cooperation of the business environment with scientific and educational organizations in order to provide the economy with qualified specialists is being updated. An innovative approach to education involves the processes of improving pedagogical technologies, a set of methods, techniques and means of teaching. The paper uses analytical methods, including content analysis, and offers a comprehensive approach. It allows us to present the methodological support of the issue under consideration in the unity of a practical-integrated approach to the learning process, a project approach within the needs of the business environment and tools of the business incubator for the development of youth innovative entrepreneurship by creating an environment in which students receive additional competencies by directly participating in the development and creation of new products. Project training solves the most important task of integrating science and business, which will give a high-quality result of cooperation in the form of an intellectual product in which the business is interested. An innovative approach in the education system will ensure the competitiveness of educational institutions and the human potential of the economy. It is important for the education system how quickly it changes organizationally and instrumentally, and how it is able to create new institutions. Subjects of the innovative infrastructure of the education system ensure socioeconomic development and transformation of the education system. Scientific and methodological support of educational organizations is represented in the unity of socio-economic, psychological and pedagogical components.
\end{abstract}

\section{Introduction}

The policy of innovative development is a priority direction of the modern economy. The processes of developing and implementing innovative development programs are being stepped up, in which it is planned to expand cooperation with scientific and educational organizations. The innovative approach reflects the current state of the education system in our country in the light of international agreements to improve it. The process of providing

\footnotetext{
*Corresponding author: tanmir12@mail.ru
} 
the economy with qualified specialists and personnel is possible in the conditions of constant development of educational systems.

Education is the most important socio-cultural institution. Innovative activities ensure the competitiveness of the institution in the market of educational services and recognition of education as the leading direction of policy implementation in the socio-economic sphere. Innovative activity is inextricably linked with the scientific and methodological activities of teachers. "Innovation" implies an innovation that differs from the standard, most common sets of methods, methods, and techniques of training. The purpose of the innovative approach to the educational process is to develop students ' ability to learn new experiences based on the purposeful formation of creative and critical thinking, experience of educational and research activities, role-playing and simulation modeling. The main indicator of innovation is a progressive beginning in the development of the University in comparison with the established traditions and mass practice [1].

\section{Materials and methods}

Innovations in the education system are associated with changes in the following areas: goals, content, methods and technologies, styles of pedagogical activity; in the organization of the educational and cognitive process; the system for monitoring and evaluating the level of education; in educational and methodological support; in the activities of students and teachers. Innovative approach in the education system is a process of improving pedagogical technologies, a set of methods, techniques and means of teaching. The main aspect of innovation is that it must be effective [2].

The branch of pedagogical knowledge-innovative pedagogical technologies classifies pedagogical innovations. There are many interpretations in pedagogy regarding this concept. Thus, V. P. Bespalko characterizes pedagogical technology as a meaningful technique for implementing the educational process. I. P. Volkov notes that pedagogical technology is a description of the process of achieving the planned learning results. Clarin interprets pedagogical technology as a system set and the order of functioning of all personal, instrumental and methodological tools used to achieve pedagogical goals. According to UNESCO, "pedagogical technology is a systematic method of creating, applying and defining the entire process of teaching and learning, taking into account technical, human resources and their interaction, which aims to optimize the forms of education" [3]. The classification of modern pedagogical technologies includes information technologies (computer, multimedia, network, remote); projective and activity technologies; creative technologies; game technologies (simulation; operational; roleplaying); technologies of personality-oriented education; ethno pedagogical technologies; collective and group methods of teaching; trainings; coaching [4].

The category "technology" differs from the concept of methodology. The methodology is a set of recommendations for the organization and conduct of the educational process. Pedagogical technology involves the design of the future educational process and the guarantee the result through the most effective and optimal sequence of actions and operations. Technology is preceded by a clear definition of the goal. It allows you to determine how to create a particular product and by what means [5].

Innovative pedagogical technologies in pedagogy related to General processes in society, global problems, integration of knowledge and forms of social existence. Accordingly, there is a need to determine the features of scientific and methodological support of innovative activities of the education system.

Within the framework of this study, an integrated approach is considered effective, including a practical integrated approach, project training in cooperation with the business environment and the development of innovative entrepreneurship through a business 
incubator, which forms students ' competencies that are in demand in the modern market. This will provide the economy with trained personnel. Currently, the specialist is expected to have characteristics that can guarantee efficiency in many activities. These characteristics are called meta-competences [6]. Meta-competences are a kind of "super structural input" that facilitates the acquisition of professional competencies and provides the ability to effectively transition to a new level of knowledge, education or professional skills. The first meta-competence is problem-solving and opportunity-creating thinking. This is the ability to understand the root cause of the problem, think about ways to get out of it, and also assume what results these paths will lead to, and what risks may arise in the process of moving forward. The second meta-competence is entrepreneurial thinking, that is, the ability to act in a situation of uncertainty and take responsibility for yourself. The third meta-competence is creativity. It is about being able to create something new. Do not just perform a sequence of actions, but also constantly make changes to them to improve the result. In modern conditions, there are often problems that no one has ever faced, and there is no ready solution. The fourth meta-competence is the ability to cooperate. To solve complex multi-level tasks, it is necessary to attract a large number of specialists working in different fields. It may be that the interests of one group of employees conflict with the interests of another. If you do not agree, do not understand each other's logic, everyone will lose. The fifth meta-competence is empathy and emotional intelligence. This is the ability to control yourself in critical situations, your own motivation and ability to go to the intended goal, acceptance of others, even in the presence of contradictions, the ability to empathize, and the ability to treat others and their interests tactfully. The sixth metacompetence is the ethics of responsibility to society and nature. Every creative decision, every result must correspond to the global challenges of the community, the country and humanity as a whole. The seventh meta-competence is the ability to concentrate and manage attention [7]. During high stress, you need to remain focused in solving problems, attention to detail. Distraction on emotional experiences can lead to a loss of time when making an urgent decision. The eighth meta-competence is flexibility, adaptability, and internal stability. Ability to adapt to constantly changing conditions, clearly assess the situation, make changes to the usual order of Affairs. The ninth meta-competence is the attitude to development, the ability to learn and relearn throughout life. Finally, metacompetence is reflection, the ability to understand the laws of one's own activity. The ability to reflect appears only when the work activity becomes a creative process, and not just a performing activity for the sake of achieving some result [8].

\section{Results}

The modern education system is characterized by the use of a high proportion of disciplines without a pronounced applied character. In the Russian educational paradigm, priority is given to training students in such a way that they should receive sufficient practical experience for successful employment. Employers note that the main task of training should be to transfer students such practical experience that would allow them to start performing labor functions with minimal time spent on retraining.

Thus, at present time in the learning process there is a need to strengthen the practical component of the educational process. There are many approaches and methods, the main purpose of which is to transform traditional training into practice-oriented. This article will focus on describing the most successful experience in improving the effectiveness of practice-oriented training at the Vladivostok state University of Economics and service. The main innovation of the University was the change in the schedule of the academic process with the maximum use of time for practical training, which, depending on the educational program, can reach one year. The combination of studying and working for a 
long time gives a number of advantages, both for the employer and for the future graduate. With this approach, the student and the teacher needed new mechanisms of interaction in the format of "mixed learning". "Mixed learning is considered as a combination of two complementary methods of knowledge transfer: traditional and e-education. This creates a powerful synergistic effect that leads to a significant increase in the effectiveness of practice-oriented training [9].

The Central concept of e-learning is an electronic course, which is a set of digital educational resources placed in a specialized content management system (Content Management System), called "e-learning environment". E-learning environment is not only a repository of educational materials translated into digital format. First, this is a new format of interaction between teachers and students, so one of the main elements of any educational environment today are forums, blogs, webinars and interactive tasks. Digital educational resources form the basis for the vast majority of existing e-courses [10].

When using an innovative approach, it is important to create such conditions in which the student can take an active personal position and fully express himself as a subject of educational activity. One of the productive technologies used in the learning process is the technology of project learning, during the implementation of which students form popular meta-competencies. The system for evaluating the student's academic results is to identify their ability to use the mastered content of education to solve practical-cognitive and communicative tasks. In this regard, students need to master the competence in the field of independent cognitive activity, which is based on the assimilation of ways to apply knowledge from various sources of information, as well as independently carry out research activities, collect and process material. As a pedagogical technology, the project method is "a combination of research, search, problem-based methods that are creative in their very essence"[11]. Project methodology is a way to achieve a didactic goal through detailed study of the problem with a real practical result. This result can be seen, understood and applied in real practice. Project-based learning develops critical and creative thinking, communication culture, and the ability to perform various social roles in joint activities; it contributes to the formation of one's own reasoned point of view. This training works for the result - creating a finished product and going out with it into society [12].

Technical, informational, and digital revolutions are rapidly replacing each other, making serious changes in the content and form of work. The lifestyle and value system of a modern employee is changing. The requirements for their skills, knowledge, and way of thinking, attitude to work, habits and social attitudes are changing. More than 100,000 new jobs are being created in the Far East. Whole industries are actively developing: mining and processing of coal, gold, ore, oil and gas; mechanical engineering; transport and logistics; forestry; agriculture and food processing; fishing and aquaculture; construction, as well as tourism and services.

The University implements the practice of leading universities in the world to include project-based learning in the educational process. Project activity is an ideal form of combining theoretical knowledge and practical skills of our future graduates - qualified specialists. The form of project-based training is not just a global trend, but also an effective educational model for training specialists who will be in demand on the labor market. Students work with social and state orders, business professionals. Students are immersed in the subject area of the project, showing great interest, initiative and presenting the finished product results to customers independently. The number of students who participated in project activities in the fall of 2020 was 1246 people. Diagram 1 shows the number of students who participated in project activities in the fall of 2020 by areas of training. 


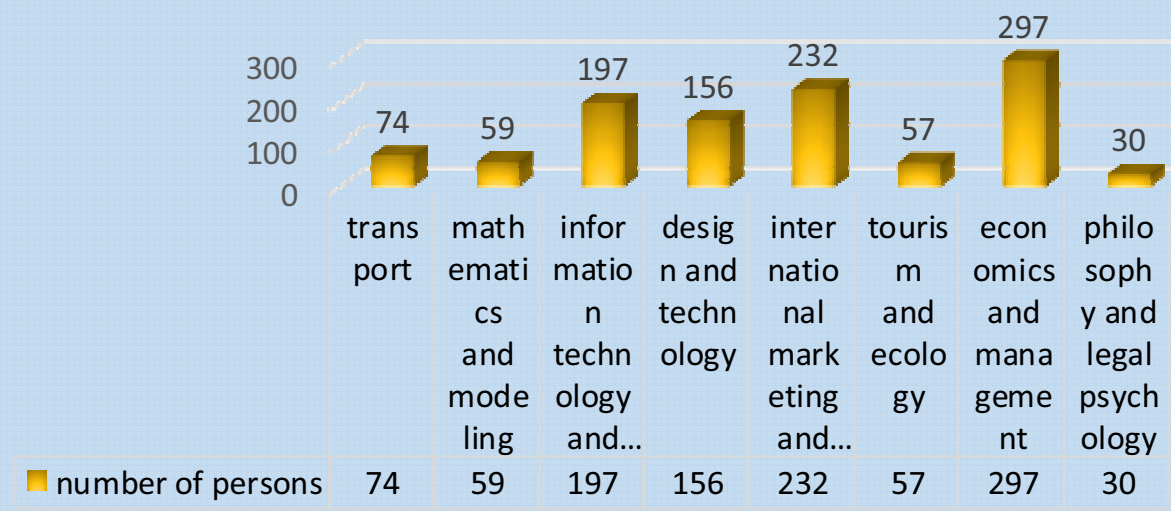

Fig. 1. The number of students who participated in project activities in the fall of 2020 .

Diagram 2 shows the number of completed projects for external orders of the business sphere and internal orders of the university, divided by departments.

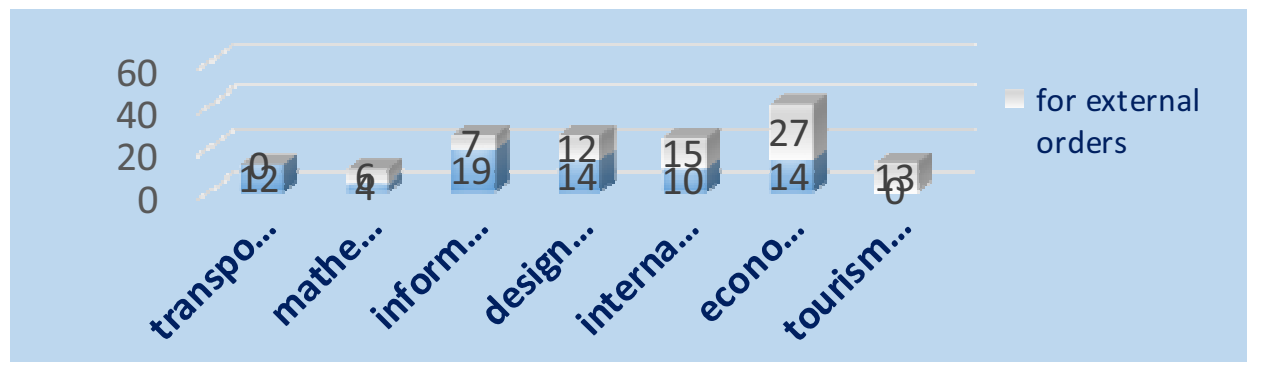

Fig. 2. The number of completed projects for external orders of the business sphere and internal orders of the university.

The most important result is that students learn to communicate not only with each other, but also with stakeholders. Students free of charge carry out most of the projects, but in the future, project activities will have full funding. Projects are implemented for specific and current business tasks and requests of the territories of the city and region. Among the projects - "business process Modeling for PJSC "Vladivostok commercial sea port", "Analysis of laboratory research data of "UNILAB", "Development of a tourist brand of a rural settlement" and so on, more than 40 initiatives in total. Students also perform work commissioned by University departments. For example, they create an image presentation of the University in several languages at the request of the information and advertising Department, organize the championship of make-up and hairdressing as part of Pacific Style Week.

At the control points, students receive recommendations from the inter-departmental expert Commission. Because of implementing projects on the orders of the business environment, teachers improve their skills, students get practical training, and customers projects [13]. Currently, the "language" of projects is spoken by large corporations, medium and small businesses. Teaching students design logic, basic tools used in project management, and teamwork. Due to this form of training, students can actually consolidate their knowledge and skills in a specific training profile. It is innovative to implement 
projects in a teamwork among different profiles. In other words, economists will be able to work with designers, lawyers with environmentalists, because the project is a dialogue of diverse specialists. Because of a large number of partners of the Vladivostok state University of Economics and business - more than 500 organizations and enterprises students, find the opportunity to self-actualize in any professional direction. The number of projects increases every year. In 2019, 240 people participated, in $2019-2020,1025$ people participated, in the spring of 2020 - 1246 people. One hundred and two leading teachers managed student project teams. More than half of the student projects were completed by external applications, that is, from representatives of regional and regional business, banking, and administrative authorities. Students and teachers have implemented hundreds of socially significant and commercial projects in various fields: economic, educational, military-historical, cross-border, tourism, and many others. By order of the regional administration, five tourist and recreational complexes have been developed, the Agency for the development of human capital in the Far East is working on routes, and a major project has been developed for the "Bikin" national Park. Students received an order from the administration of the Primorsky territory to monitor 300 more tourist routes. Students of the Institute of service, fashion and design create projects for urban improvement, and students of the profile "Service in aviation "begin to develop business etiquette for the airline "Aurora" and create a new image of its employees. Design and development of a system of mobile services for small and medium-sized businesses. The smart cities for the Arctic project has developed a mobile application Analysis of smart technologies for the Arctic zone of Russia. The geographical location of the Russian Far East region determines the effectiveness of attracting foreign students to project-based training. In particular, students from China participated in the strategically important project of water Park construction "Marketing research of the project of construction of the multifunctional recreation complex "Eastern Aqua Paradise" on Russian Island, Primorsky Kray: analysis of the water Park market", and they provided significant assistance to the project by collecting statistical information on East Asian countries. The main methods of performing the research part of the project were developing questionnaires, interviewing respondents, processing analytical information, preparing reports. Students-participants of the project — focus on the acquired skills and the ability to solve real problems for business.

The main advantage of project activities is their practical orientation and focus on visible results [14].

\section{Discussion}

"Project activity" is an opportunity for students to be acquainted with real business problems. Students who participated in the project noted the unique opportunity to go beyond the narrow educational environment and develop a professional portfolio. The course goes beyond the University educational standard and allows you to get skills such as stress tolerance and multitasking, expanding professional tools, developing skills of selforganization and time management. In the context of the pandemic, a number of projects were prepared online and remote work contributed to the development of independence and rational use of time, communication skills with the team and the expert Commission on videoconferencing [15].

For representatives of socially responsible businesses, it is very important to participate as mentors for the younger generation and determine in advance the personnel for the formation of a personnel reserve, attract future professionals to draw up business plans, think through marketing strategies. This is an opportunity to directly participate in the training of future employees, developing their competencies that will be particularly in 
demand in the regional business environment. Such opportunities for joint productive work with humanistic goals are especially valuable now, when business is going through very difficult times due to restrictive measures. External customers update the agenda and actively participate in evaluating product results. The University forms a regional innovation infrastructure of the education system by entering into an agreement with the Association "business club "Avangard" on mutually beneficial cooperation in the direction of training professional staff and increasing the practice-oriented educational process. Project training solves the most important task-the integration of science and business, which will give a high-quality result of this cooperation in the form of an intellectual product in which the business is interested. The University, as a scientific organization, will be able to find certain growth points in the tasks that business sets for it in the field of scientific research. This form of scientific and methodological support for the development of regional innovation infrastructure of General education allows you to quickly and effectively distribute innovative practices in the educational system. Subjects of the innovative infrastructure of the education system ensure socio-economic development [16].

By the decision of the Federal Agency for education, with the support of the Ministry of education and science and the Ministry of economic development of the Russian Federation, an innovative business incubator was established at the University. It is the first and only innovative business incubator in Primorsky Kray. Any student studying in Vladivostok can become a resident of the incubator. Specialists of the business incubator advise on various production issues. The business incubator provides residents with information support on its website. All residents actively communicate with each other and work closely together. The incubator is used for a digital laboratory for 3D modeling and prototyping. The purpose of the business incubator is to support small businesses in the region at an early stage of their activities by providing them with consulting, educational, accounting, legal, economic and other services necessary for successful business development. The priority of the University's business incubator is to develop innovative youth entrepreneurship by creating an environment in which students can acquire additional competencies by directly participating in the development and creation of new products and services. This process consists of three stages, each of which has its own characteristics and specific goals. At the first stage, students are helped to formulate ideas, set business goals, and form teams to implement them. At the second stage, viable ideas and promising teams are selected. The format of this stage is competitions. This stage helps teams transform an idea into a business project and present it competently to experts. At the third stage, the business incubator provides formed project teams with all types of consulting services, as well as helps them find investments.

The incubator actively engages students in various competitive events: national and regional Championships and games, meetings with representatives of government agencies and business communities, seminars, trainings, and much more. Among them are the open championship "Global Management Challenge", "Russian Startup Tour", the Startup School "Sprint", regional competitions in the simulation game "Modeling of Economics and management", the regional competition "Best young entrepreneur".

\section{Conclusion}

The use of innovative educational technologies has caused an increased interest of students in the learning process. In this case, we can reasonably talk about increasing motivation for the learning process for both teachers and students. In the future, the prospects for educational innovations will be associated with improving the quality of education. Scientific and methodological support of educational organizations that have the status of Federal and regional innovation platforms that implement innovative scientific and applied 
projects and programs implies the most conscious interaction of the parties involved with the division of responsibility for the implementation of the process and obtaining results [17].

Scientific and methodological support is a scientifically based, specially organized process of interaction of subjects aimed at overcoming professional difficulties and meeting the professional needs of educational workers. When determining the directions of scientific and methodological support for the development of innovative infrastructure of education, all aspects of the development of the education system should be taken into account. Scientific and methodological support of the considered process is represented in the unity of its socio-economic, psychological and pedagogical components[18]. This approach will allow Russian education to maintain its competitive position in relation to the education of the best universities in the United States and Europe.

\section{References}

1. M. Al Kassiri, and T. Čorejová, CBU International Conference Proceedings, 3, 271275 (2015)

2. T. Khavenson, D. Koroleva, and A. Lukina, HSE Working papers from National Research University Higher School of Economics Published in WP BRP Series: Education / EDU, 1-23 (July, 2019)

3. A.E. Paltov, Innovative educational technologies (Publishing house of VISU, Vladimir, 119, 2018)

4. C. D. Baican, Proceedings Education, 27-32 (2017)

5. D.A. Smirnov, V.P. Pavlov, and M.S. Trofimov, European Research Studies Journal, (21)4, 567-576 (2018)

6. S.A. Mikhailichenko, Yu. Buryak, Yu.A. Afanaskova, Metacompetencies as the basis for successful self-realization of graduates in the labor market (Belgorod state technological University named after V. G. Shukhov, 94-101, 2016)

7. L. Earl, and H. Timperley, OECD Education Working Papers from OECD Publishing (2015)

8. L. Hougaz, Entrepreneurs Creating Educational Innovation (Springer, 2020) DOI: 10.1007/978-3-030-28655-2 [ http://www.springer.com/9783030286552]

9. J.J. Heckman, T. Kauts, Labour Economics, 19(4), 451-464 (2012)

10. T. Bolli, U. Renold, and M. Wörter, Economics of Innovation and New Technology, 27(2), 107-131 (2018)

11. A. Tur-Porcar, A. Mas-Tur, and E. Malonda, Sustainability, 9(9), 1-11 (2017) [https://www.mdpi.com/2071-1050/9/9/1626/pdf]

12. N. Mahapoonyanont, GATR Journals from Global Academy of Training and Research (GATR) Enterprise, 12 (2020)

13. G. Selyanskaya, Economy of region, 1(1), 157 - 165 (2011)

14 A. Gromoff, J. Stavenko, and N. Kazantsev, Far East Journal of Psychology and Business 8(2), 53-65 (2012) [http://www.fareastjournals.com/files/FEJPBV8N2P4.pdf]

15. A. Sitko-Lutek, A. Karasek, ToKnowPress (2013) [http://www.toknowpress.net/ISBN/978-961-6914-07-9/papers/S1_76-85.pdf]

17. M. Junge, B. Severgnini, A. Sørensen, Working Papers from Copenhagen Business School, Department of Economics, 32 (2012) 
18. O.A. Ievsieieva, Business Inform, 12, 341-346 (2012)

19. S.N. Gudak, Journal "Region: Economics and Sociology", 1 (2010) 